\title{
INCLUSÃO DOS IDOSOS EM DISCIPLINAS DE CURSOS DE GRADUAÇÃO
}

Stephanie de Carvalho Souza; Universidade Federal do Rio Grande do Sul; stephaniesouzapoa@hotmail.com

Arthur Zasso Krause; Universidade Federal do Rio Grande do Sul; arthur_krause@hotmail.com Maira Rozenfeld Olchik; Universidade Federal do Rio Grande do Sul; mairarozenfeld@hotmail.com Adriane Ribeiro Teixeira; Universidade Federal do Rio Grande do Sul; adriane.teixeira@gmail.com

\section{RESUMO}

Introdução: A UFRGS foi uma das pioneiras em projetos de inclusão de idosos. Atualmente conta com a Universidade Aberta para Pessoas Idosas (UNAPI/UFRGS), um programa composto por várias iniciativas para idosos no ambiente universitário. Objetivos: Relatar a participação de idosos em disciplinas regulares da graduação, via projeto piloto. Metodologia: Para o desenvolvimento do projeto, foram criados editais para ingresso em disciplinas regulares dos cursos de graduação em Comunicação Social (Jornalismo Esportivo), Educação Física (Práticas Corporais e Envelhecimento) e Fonoaudiologia (Avaliação Audiológica I e Intervenção Fonoaudiológica em Envelhecimento). Para participar, os idosos deveriam comprovar escolaridade (ensino médio ou curso superior). Resultados: Cinco pessoas foram selecionadas para participar das disciplinas em 2019, sendo três com ensino superior completo. Todas estiveram presentes nas aulas teóricas e práticas ao longo do semestre letivo, realizando as atividades em conjunto e interagindo com os alunos da graduação. Os professores responsáveis pelas disciplinas tinham atuação e formação em envelhecimento, preparando os alunos para o acolhimento e a integração dos idosos nas turmas. A partir dos resultados obtidos, foi criado um novo projeto, já apresentado para a Universidade, para que idosos possam participar regularmente das disciplinas dos diferentes cursos de graduação. Conclusão: Verificou-se que a inclusão dos idosos promoveu o convívio intergeracional e a inclusão na universidade, uma vez que todos participaram das aulas e atividades propostas em conjunto com os alunos de graduação. Enquanto para os já graduados foi uma oportunidade de atualização profissional, para aqueles com ensino médio foi a oportunidade de frequentarem o ambiente universitário.

Palavras-chave: idoso; educação; envelhecimento. 